
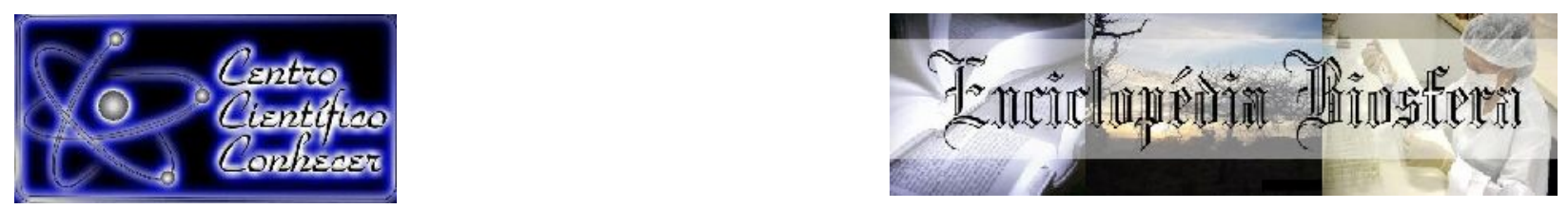

\title{
EFEITO DA QUEIMADA SOBRE A ATIVIDADE ENZIMÁTICA EXTRACELULAR DE CEPAS DE ACTINOBACTÉRIAS ISOLADAS DE SOLO DA REGIÃO SEMIÁRIDA DO CEARÁ
}

Filipe de Abreu Vieira ${ }^{1}$, Fernando Gouveia Cavalcante ${ }^{2}$, Franciandro Dantas dos Santos $^{3}$, Suzana Cláudia Silveira Martins ${ }^{4}$, Claudia Miranda Martins ${ }^{4}$

\author{
${ }^{1}$ Bacharel em Ciências Biológicas pela Universidade Federal do Ceará (UFC) \\ ${ }^{2}$ Mestre e estudante de doutorado pelo Programa de Pós-Graduação em Ecologia e \\ Recursos Naturais da Universidade Federal do Ceará (UFC) \\ ${ }^{3}$ Doutor em Ecologia e Recursos Naturais (UFC) \\ ${ }^{4}$ Professora Doutora na área de microbiologia do Departamento de Biologia da \\ Universidade Federal do Ceará (UFC) \\ E-mail: fernandogouveia.c@gmail.com
}

Recebido em: 15/11/2021 - Aprovado em: 15/12/2021 - Publicado em: 30/12/2021
DOI: 10.18677/EnciBio_2021D23
trabalho licenciado sob licença Creative Commons Attribution-NonCommercial-NoDerivatives 4.0 International License

\section{RESUMO}

A biodiversidade é reconhecida como o principal fator que afeta o funcionamento do ecossistema e a estabilidade funcional do solo. As atividades humanas estão levando a uma redução rápida e significativa da biodiversidade. A maioria dos processos do solo é realizada por grupos de espécies microbianas que podem amortecer as mudanças induzidas pela atividade humana. O surgimento de incêndios florestais, como as queimadas, pode resultar em efeitos negativos na comunidade microbiana do solo levando a degradação do mesmo. Dentre os microrganismos do solo, destacam-se as actinobactérias, que são conhecidas por sua ampla produção de enzimas que desempenham diversas funções ecológicas. $O$ objetivo desse trabalho foi investigar como as queimadas afetam o potencial enzimático de actinobactérias isoladas de solos da região semiárida do nordeste brasileiro. Vinte cepas de actinobactérias, isoladas de solo antes e depois de aplicação de fogo (queimada), foram avaliadas quanto à produção extracelular de amilase, celulase e xilanase. Todas as cepas apresentaram atividade amilolítica, por sua vez 14 cepas apresentaram atividade celulolítica e 10 cepas apresentaram atividade xilanolítica. A atividade amilolítica foi negativamente afetada pela queimada de modo que os índices enzimáticos das cepas isoladas após o incêndio foram significativamente menores ao da área antes da queimada. As atividades celulolítica e xilanolítica foram aumentadas no solo submetido ao fogo. Conclui-se que a queimada afetou significativamente a produção das enzimas hidrolíticas extracelulares de cepas de actinobactérias isoladas do solo.

PALAVRAS-CHAVE: Incêndios florestais; microbiota do solo; serviços ecossistêmicos. 


\title{
EFFECT OF THE BURNING ON EXTRACELLULAR ENZYMATIC ACTIVITY OF ACTINOBACTERIAL STRAINS ISOLATED FROM SOIL IN THE SEMIARID REGION OF CEARÁ
}

\begin{abstract}
Biodiversity is recognized as the main factor affecting ecosystem functioning and soil functional stability. Human activities are leading to a rapid and significant reduction in biodiversity. Most soil processes are carried out by microbial groups that can dampen changes induced by human activity. The emergence of forest fires can result in negative effects on the soil microbial community, leading to its degradation. Among the soil microorganisms, actinobacteria stand out, which are known for their diverse enzyme production that perform various ecological functions. The objective of this work was to investigate how forest fires affect the enzymatic potential of actinobacteria isolated from soils in the semiarid region of northeastern Brazil. Twenty actinobacterial strains, that were isolated from soil before and after application of fire, were evaluated for amylase, cellulase and xylanase extracellular production. All strains showed amylolytic activity, in turn 14 strains showed cellulolytic activity and 10 strains showed xylanolytic activity. The amylolytic activity was negatively affected by the burning so that the enzymatic indexes of the strains isolated after the fire were significantly lower than that of the area before the burning. Cellulolytic and xylanolytic activities were increased in soil subjected to fire. It is concluded that forest fire significantly affected the production of extracellular hydrolytic enzymes of actinobacteria strains isolated from the soil.
\end{abstract}

KEYWORDS: Forest fires; ecosystem services; soil microbiota.

\section{INTRODUÇÃO}

O solo garante a provisão de vários serviços ecossistêmicos, regulando processos naturais e fornecendo funções essenciais para o habitat dos organismos que nele vivem (GREINER et al., 2017; GREINER et al., 2018). A biota do solo participa do processo de formação do mesmo transformando a matéria orgânica que resulta na produção de substâncias húmicas promovendo a agregação das partículas (LEHMANN et al., 2017).

Os incêndios florestais, também conhecidos como queimadas são uma das principais causas da destruição e renovação da vegetação podendo ser causados por fatores ambientais ou antrópicos. As queimadas de origem antrópica passaram a ser a principal causa de desmatamento no Brasil, que se acentuou nos últimos anos, sendo uma ameaça à conservação da biodiversidade (SOUZA; PEREIRA, 2019).

Muitas propriedades físicas, químicas, mineralógicas e biológicas do solo podem ser afetadas por incêndios florestais e tais efeitos são principalmente decorrentes da gravidade da queima, que consiste nos picos de temperatura e na duração do incêndio (SINGH et al., 2017 ; ALCAÑIZ et al., 2018).

O impacto das queimadas resulta em uma exposição prolongada do solo ao fogo que reflete diretamente na comunidade edáfica, pois ocasiona um aumento significativo do $\mathrm{pH}$, carbono orgânico total, nitrogênio total e matéria orgânica nos solos queimados (RODRÍGUEZ et al., 2017; PRENDERGAST-MILLER et al., 2017), levando ao aumento da comunidade microbiana do solo que responde com maior atividade e produção de biomassa (RODRíGUEZ et al., 2018).

As comunidades microbianas presentes no solo afetam a sua qualidade, proporcionando um ambiente estável (APARICIO et al., 2017; BUNEMANN et al., 2018). Dentre os microrganismos do solo, encontram-se as actinobactérias que são 
bactérias aeróbias Gram-positivas, amplamente distribuídas no solo, formando um filo cosmopolita que inclui bactérias em forma de bastonetes e filamentosas, que também desempenham um papel importante como simbiontes e como patógenos em comunidades microbianas associadas a plantas (NOUIOUI et al., 2018; HAMEDI et al. 2019).

Essas bactérias são quimioheterotróficas e podem utilizar polímeros complexos presentes no ambiente como fonte de energia produzindo metabólitos secundários que atuam na ciclagem de biomassa, degradação de substâncias orgânicas, polissacarídeos, gorduras, proteínas e materiais recalcitrantes (MEIJ et al., 2017). Actinobactérias estão presentes no solo da região semiárida do nordeste brasileiro (CAVALCANTE et al., 2017) sendo adaptadas as condições de estresse abiótico características desse ambiente tais como baixa disponibilidade hídrica, período de estiagem prolongado, temperaturas elevadas, alto índice de radiação solar e limitação de recursos (MUNOZ-ROJAS et al., 2016).

As adaptações das actinobactérias ao longo do seu período evolutivo incluem a produção enzimas extracelulares capazes de degradar carboidratos complexos encontrados nos vegetais que são os principais componentes de matéria orgânica do solo (LACOMBE-HARVEY et al., 2018), o que representa uma vantagem evolutiva em relação aos outros microrganismos.

A atividade de enzimas hidrolíticas tais como amilase, celulase e xilanase vêm sendo observadas nas actinobactérias graças a sua importância ecológica na ciclagem de nutrientes, bem como no potencial biotecnológico para utilização industrial e bioremediação de solos degradados (APARICIO et al., 2017; GOSAl et al., 2018). Além disso, a atividade enzimática microbiana também é considerada bioindicadora de distúrbios que afetam o solo (MENDES et al., 2015).

Diante do exposto o objetivo desse trabalho foi investigar como as queimadas afetam a atividade amilolítica, celulolítica e xilanolítica de actinobactérias isoladas de solos da região semiárida do nordeste brasileiro.

\section{Local de estudo e origem das cepas}

\section{MATERIAL E MÉTODOS}

Os microrganismos utilizados nesse estudo são provenientes de 20 amostras de solo que foram gentilmente cedidas pelo Centro Nacional de Prevenção e Combate a Incêndios Florestais (Prevfogo) e são procedentes da Fazenda Normal,

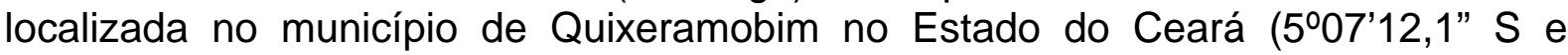
3910'33,3" W) onde uma área de 1 hectare foi isolada por uma faixa de 3 metros sem vegetação (aceiro florestal) para simulação do incêndio. O solo foi coletado nos períodos antes e depois da queimada utilizando os mesmos pontos amostrais com 10 amostras para cada período, numa profundidade de $0-20 \mathrm{~cm}$.

O solo da área é um Luvissolo Crômico Pálido Típico, vegetação Caatinga hiperxerófila e relevo plano a suave ondulado. O clima é classificado como Tropical Quente Semiárido, apresenta pluviosidade média anual de 600 a $800 \mathrm{~mm}$, concentrada nos meses de fevereiro a abril e temperatura média de $26^{\circ} \mathrm{C}$ a $42^{\circ} \mathrm{C}$ (ARAUJO, 2011).

As cepas foram previamente isoladas e caracterizadas com base em seus aspectos culturais e se encontram depositadas na coleção de culturas do Laboratório de Microbiologia Ambiental do Departamento de Biologia da Universidade Federal do Ceará. Foram selecionadas as cepas QB06, QB11, QB24, QB65, QB68, QB83, QB114, QB142, QB190, QB191 (amostras de solo antes da queimada) e QB32, QB45, QB55, QB93, QB102, QB104, QB153, QB183, QB186, 
QB189 (amostras de solo depois da queimada). O critério de seleção das cepas para esse estudo baseou-se na diferença das características culturais (cor dos micélios) que essas apresentaram em relação às demais.

\section{Atividade enzimática}

A determinação da atividade amilolítica seguiu a metodologia descrita por Mishra e Behera (2008). As cepas foram inoculadas em placas contendo o meio ágar amido que foram incubadas a $28^{\circ} \mathrm{C}$ por 10 dias. Após o crescimento das colônias, foram adicionados $10 \mathrm{~mL}$ da solução de lugol (1\% iodo em $2 \%$ iodeto de potássio) nas placas e a produção da enzima amilase foi evidenciada pela descoloração do meio, formando uma zona translúcida em torno da colônia (halo de hidrólise do amido).

A atividade celulolítica foi avaliada segundo Hendricks et al. (1995), utilizando meio de cultivo suplementado com carboximetilcelulose $\left(\mathrm{NaNO}_{3}: 3,0 \mathrm{~g} \mathrm{.}\right)^{-1} ; \mathrm{K}_{2} \mathrm{HPO}_{4}$ : 1,0 g. L $\mathrm{L}^{-1} ; \mathrm{MgSO}_{4}: 0,5 \mathrm{~g} . \mathrm{L}^{-1} ; \mathrm{KCl}: 0,5 \mathrm{~g} . \mathrm{L}^{-1} ; \mathrm{FeSO}_{4} \cdot 7 \mathrm{H}_{2} \mathrm{O}: 10,0 \mathrm{mg} \cdot \mathrm{L}^{-1} ; \mathrm{CMC}^{-10,0} \mathrm{~g}$. $\mathrm{L}^{-1}$; ágar: $20,0 \mathrm{~g}$. $\mathrm{L}^{-1}$ ) e a atividade xilanolítica seguiu a metodologia descrita por Breccia et al. (1995) utilizando meio suplementado com xilana (NaNO3: 3,0 g. $\mathrm{L}^{-1}$; $\mathrm{K}_{2} \mathrm{HPO}_{4}: 1,0$ g. $\mathrm{L}^{-1} ; \mathrm{MgSO}_{4}: 0,5 \mathrm{~g} . \mathrm{L}^{-1} ; \mathrm{KCl}: 0,5 \mathrm{~g} . \mathrm{L}^{-1} ; \mathrm{FeSO}_{4} \cdot 7 \mathrm{H}_{2} \mathrm{O}: 10,0 \mathrm{mg} . \mathrm{L}^{-1}$; xylan: $10,0 \mathrm{~g} \cdot \mathrm{L}^{-1}$; ágar: $\left.20,0 \mathrm{~g} . \mathrm{L}^{-1}\right)$. As cepas foram inoculadas e incubadas a $28^{\circ} \mathrm{C}$ por 10 dias. Após a incubação, foram adicionados $10 \mathrm{~mL}$ de solução de vermelho congo a $0,5 \%$ em cada placa, deixando-se agir por 15 minutos a $28 \circ \mathrm{C}$. Posteriormente, o excesso da solução foi drenado e $10 \mathrm{~mL}$ de solução de $\mathrm{NaCl}(2 \mathrm{M})$ foram adicionados em cada placa, deixando-se agir por 30 minutos. As atividades celulolíticas e xilanolíticas foram detectadas pela formação de um halo alaranjado ao redor das colônias. Todos os testes foram realizados em quadruplicata com duas repetições e as cepas foram inoculadas na forma de spots.

\section{Análise dos dados}

O índice enzimático (IE) foi calculado para quantificar a atividade enzimática (método semiquantitativo) utilizando-se a seguinte equação: IE = Dh/Dc. Sendo Dh o diâmetro em $\mathrm{mm}$ do halo de hidrólise e Dc o diâmetro em $\mathrm{mm}$ da colônia (STAMFORD et al., 1998).

Os dados obtidos a partir do cálculo dos índices enzimáticos foram submetidos ao teste de normalidade, homogeneidade de variâncias e logo em seguida a análise de variância (ANOVA, $p<0,05$ ) para avaliar a atividade enzimática do solo antes e depois da queimada. Também foi construído um diagrama de similaridade utilizando o algoritmo UPGMA e a distância euclidiana como parâmetro de similaridade. Os dados foram analisados no software estatístico PAST e os gráficos foram plotados no software Prism GraphPad 5.

\section{RESULTADOS E DISCUSSÃO}

Os resultados mostram que a queimada altera o potencial enzimático das cepas de actinobactérias. A partir da ANOVA foi possível observar que os índices enzimáticos obtidos das cepas isoladas de solo antes e depois do fogo são significativamente diferentes $(\mathrm{p}<0,05)$ para as três enzimas estudadas (Figura 1). 
FIGURA 1. Médias e desvios-padrão da atividade enzimática das cepas de actinobactérias isoladas do solo antes e depois da queimada

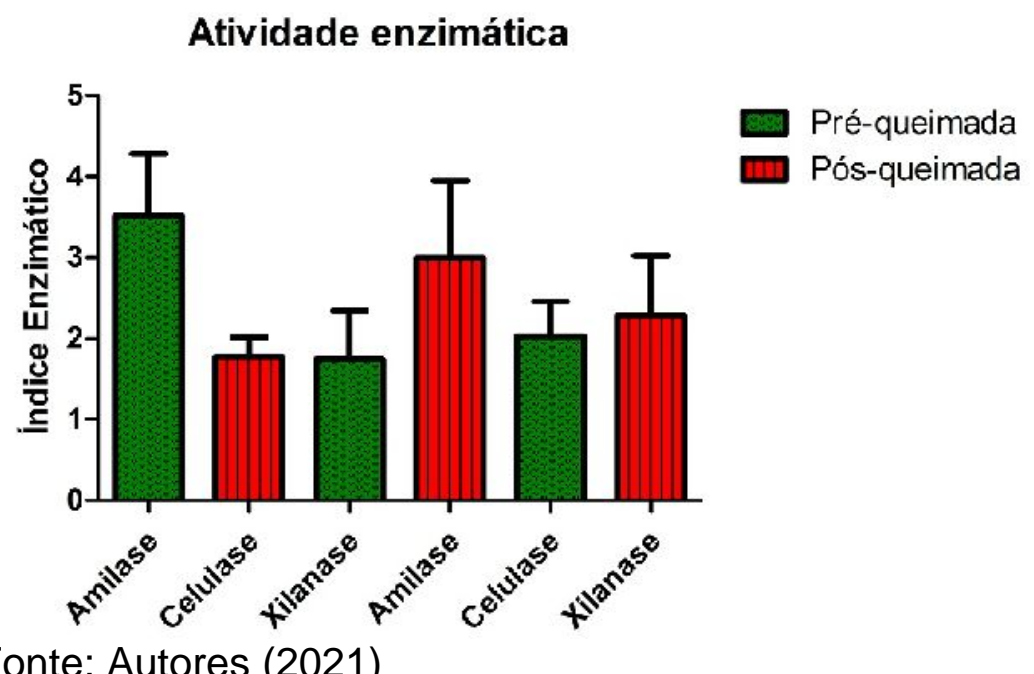

\section{Atividade amilolítica}

Com relação a atividade amilolítica, todas as cepas utilizadas nesse estudo apresentaram produção de amilase com destaque para a cepa QB114 que apresentou a menor média de índice enzimático $(\mathrm{IE}=2,22)$ comparado ao padrão demonstrado pelas demais cepas. As cepas das amostras pós-queimada apresentam valores médios de IE menores que as cepas pré-queimada, onde a cepa QB45 apresentou o menor IE $(2,41)$ e a QB 32 apresentou o maior valor $(4,48)$.

A atividade amilolítica apresentou diferença significativa na análise de variância considerando conjunto de cepas antes e depois da aplicação do fogo, indicando que a alta temperatura provocada pelas queimadas influencia a atividade enzimática da microbiota do solo. Essa alteração pode trazer prejuízos para a fertilidade do solo uma vez que essas enzimas participam da transformação dos substratos orgânicos. A Figura 2 mostra as médias e amplitudes dos IE da atividade amilolítica das cepas antes e depois da queimada.

FIGURA 2. Box-plot da atividade amilolítica das cepas de actinobactérias isoladas do solo antes e depois da queimada

Atividade amilolítica

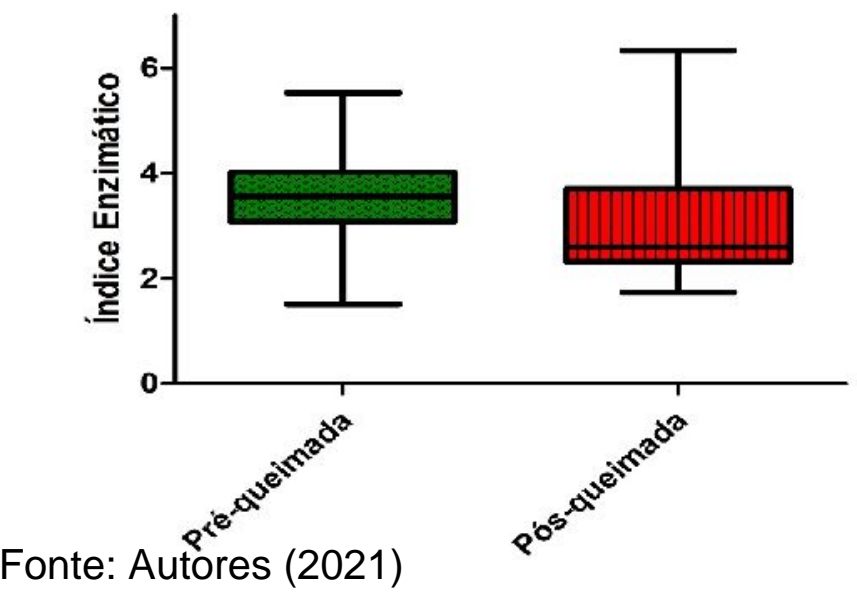


Nota-se que o uso do fogo provocou a redução na média dos IE das cepas de actinobactérias, o que demonstra o efeito deletério nas funções que essas bactérias podem oferecer para o ecossistema. Por outro lado, a amplitude dos valores de IE das cepas isoladas da área pós-queimada foi maior indicando maior variabilidade na produção enzimática por essas cepas.

Actinobactérias na região semiárida do Ceará já são conhecidas como produtoras de amilase em outros estudos (ALVES et al., 2016; LOPES et al., 2018). A atividade amilolítica leva a degradação de amido em amilose e amilopectina. Entretanto, o calor proveniente do fogo pode levar a enzima a sua desnaturação e a calcinização do substrato leva ao decaimento do amido no solo, ocasionando a diminuição da produção de amilase pelas actinobactérias (KHVEDELIDZE et al., 2017; HAMEED et al., 2017; VAIKUNDAMOORTHY et al., 2018).

Por outro lado, aumento de matéria orgânica, incluindo o amido, pode levar a uma maior atividade enzimática pela comunidade microbiana do solo que tem a capacidade de adaptar-se às mudanças ambientais através da modulação da sua composição e funções metabólicas (RODRíGUEZ et al., 2018). A menor atividade amilolítica no solo após a queimada pode ter sido ocasionada pelas altas temperaturas provenientes do incêndio, de modo que as cepas sofreram modulações diferentes na sua produção de amilase como mecanismo de adaptação a esse estresse.

Além disso, o fogo reduz drasticamente a matéria orgânica do solo provocando um aumento da competição entre os microrganismos que adotam estratégias de buscas por substratos orgânicos incluindo a maior produção de enzimas extracelulares, o que justifica os maiores valores de IE no solo após o uso do fogo.

\section{Atividade celulolítica}

Dentre as 20 cepas testadas apenas 14 apresentaram atividade celulolítica, destacando-se as actinobactérias do período pós-queimada com oito cepas que apresentaram as maiores médias de índice enzimático. Apenas seis cepas da área pré-queimada apresentaram atividade celulolítica e as médias dos IE foram menores comparados à área após a utilização de fogo.

Os IE da atividade celulolítica entre os tratamentos pré e pós queimadas foram estatisticamente diferentes de acordo com a ANOVA, o que indica um efeito do fogo sobre o potencial enzimático das actinobactérias em relação a produção de celulase. Os dados da atividade celulolítica estão graficamente apresentados na Figura 3. 
FIGURA 3. Box-plot da atividade celulolítica das cepas de actinobactérias isoladas do solo antes e depois da queimada

Atividade celulolítica

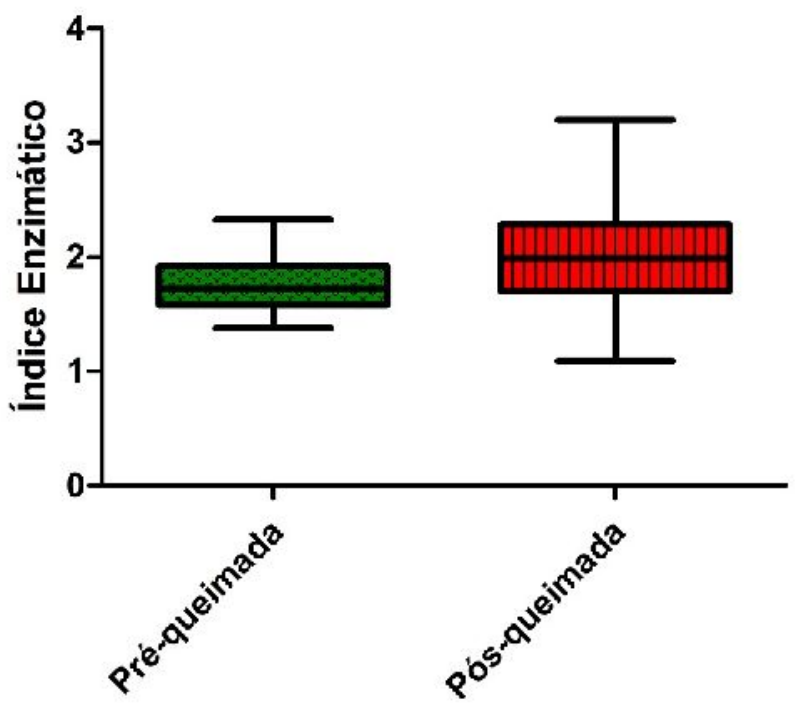

Fonte: Autores (2021)

A atividade celulolítica mostrou-se mais expressiva nas cepas isoladas de solo submetido ao fogo. Os valores médios dos IE, bem como a amplitude dos dados foram maiores na área pós-queimada sugerindo um aumento do potencial enzimático das actinobactérias por esse agente físico. Bactérias e fungos são considerados principais produtores de celulases na natureza (GUPTA et al., 2012) e na região semiárida do Ceará actinobactérias são apontadas como produtoras de enzimas celulolíticas (ALVES et al., 2016; LOPES et al., 2018).

Actinobactérias produzem celulases com propriedades bioquímicas peculiares, com grande estabilidade e alta atividade em condições de $\mathrm{pH}$ e temperaturas mais extremas (OLIVEIRA et al., 2016). Neste aspecto, o efeito da temperatura na atividade de celulases é bastante importante e as enzimas das actinobactérias apresentam, na grande maioria, valores ótimos de atividade na faixa de 40 a $60^{\circ} \mathrm{C}$ (JANG; CHEN, 2003; LIMA et al., 2005), o que pode estar associado ao maior número de cepas produtoras dessa enzima no solo após o incêndio.

Conforme discutido anteriormente, o fogo transforma os substratos orgânicos do solo em minerais e cinzas e com isso provoca maior competição da microbiota por recursos. As actinobactérias são conhecidas por aumentar sua produção de enzimas extracelulares em resposta ao estresse ambiental, o que está de acordo com os resultados obtidos.

O fato de as cepas apresentarem menor atividade celulolítica do que amilolítica na área antes da queimada pode estar relacionado com as características da celulose e a forma como ela está disponível no ambiente, pois é constituinte da parede celular dos vegetais e é o maior carboidrato sintetizado por eles, sendo um polissacarídeo mais complexo que o amido (BAYER; LAMED, 1992).

\section{Atividade xilanolítica}

Dentre as enzimas estudadas a xilanase foi a que apresentou menor potencial, pois apenas dez cepas mostraram atividade xilanolítica, sendo quatro 
cepas da área pré-queimada e seis cepas do período pós-queimada. Os dados da atividade xilanolítica estão graficamente apresentados na Figura 4.

FIGURA 4. Box-plot da atividade xilanolítica das cepas de actinobactérias isoladas do solo antes e depois da queimada

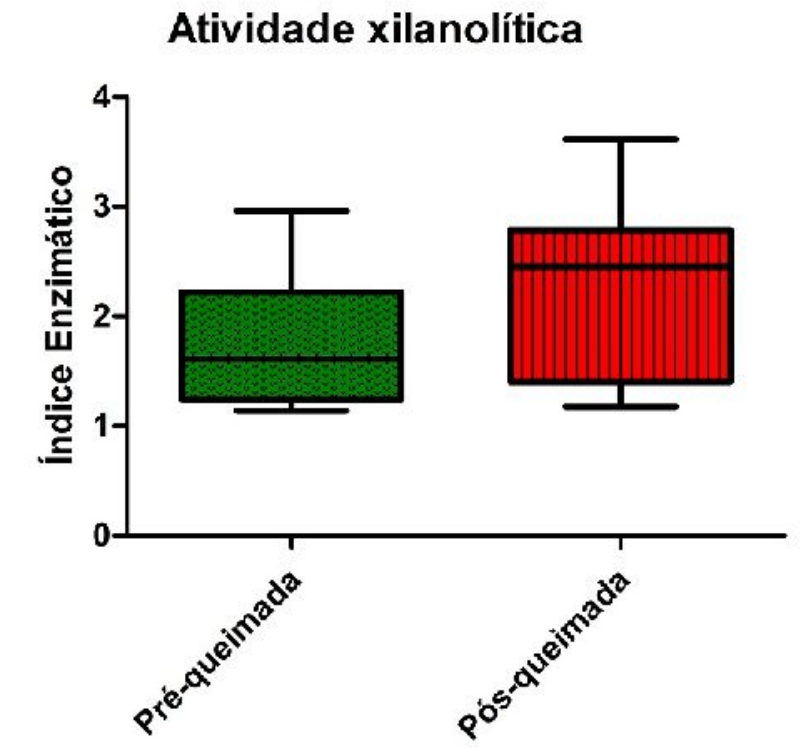

Fonte: Autores (2021)

Houve diferença estatística entre os tratamentos e a atividade xilanolítica das cepas aumentou no solo da área pós-queimada. Assim como na atividade celulolítica, as cepas originadas do solo após a aplicação de fogo parecem ter maior potencial para produção enzimática em resposta à pressão abiótica as quais foram submetidas.

Nos estudos de Borjesson et al. (2018) a atividade da xilanase aumentou gradualmente a medida em que a temperatura aumentou até o valor de $60^{\circ} \mathrm{C}$, tendo alta efetividade em degradar os polímeros de xilana que são construídos por uma cadeia linear de unidades de xilose unidos através de uma ligação $\beta-1,4$, onde os grupos laterais podem ser substituídos por ácidos urônicos, ferúlicos ou arabinofuranose, o que dá característica rígida a xilana. As características da xilana refletem a grande variedade de enzimas com atividade de xilanase (COLLINS et al., 2005).

A atividade da xilanase de actinobactérias do gênero Thermomonospora sp. é maior na temperatura de $70^{\circ} \mathrm{C}$, produzindo atividade até $80^{\circ} \mathrm{C}$ (GEORGE et al., 2001), por sua vez os estudos de Sanjivkumar et al. (2017) observaram que a atividade de xilanases extracelulares produzidas por actinobactérias do gênero Streptomyces sp. era maior na temperatura de $40^{\circ} \mathrm{C}$.

As xilanases produzidas por fungos apresentam temperatura ótima de $50^{\circ} \mathrm{C}$, variando até $80^{\circ} \mathrm{C}$ (BEDADE et al., 2017 ; KUMAR; SHUKLA, 2018). O fato de essa enzima estar associada a temperaturas mais elevadas pode explicar os valores de IE mais elevados, principalmente nas cepas isoladas do solo após a queimada. $O$ dendrograma da Figura 5 mostra as cepas agrupadas de acordo com a similaridade de seu potencial enzimático considerando as três enzimas e os seus respectivos valores de IE. 
FIGURA 5. Dendrograma de similaridade entre as cepas isoladas do solo pré-queimada (verde) e pós-queimada (vermelho) considerando as atividades amilolítica, celulolítica e xilanolítica

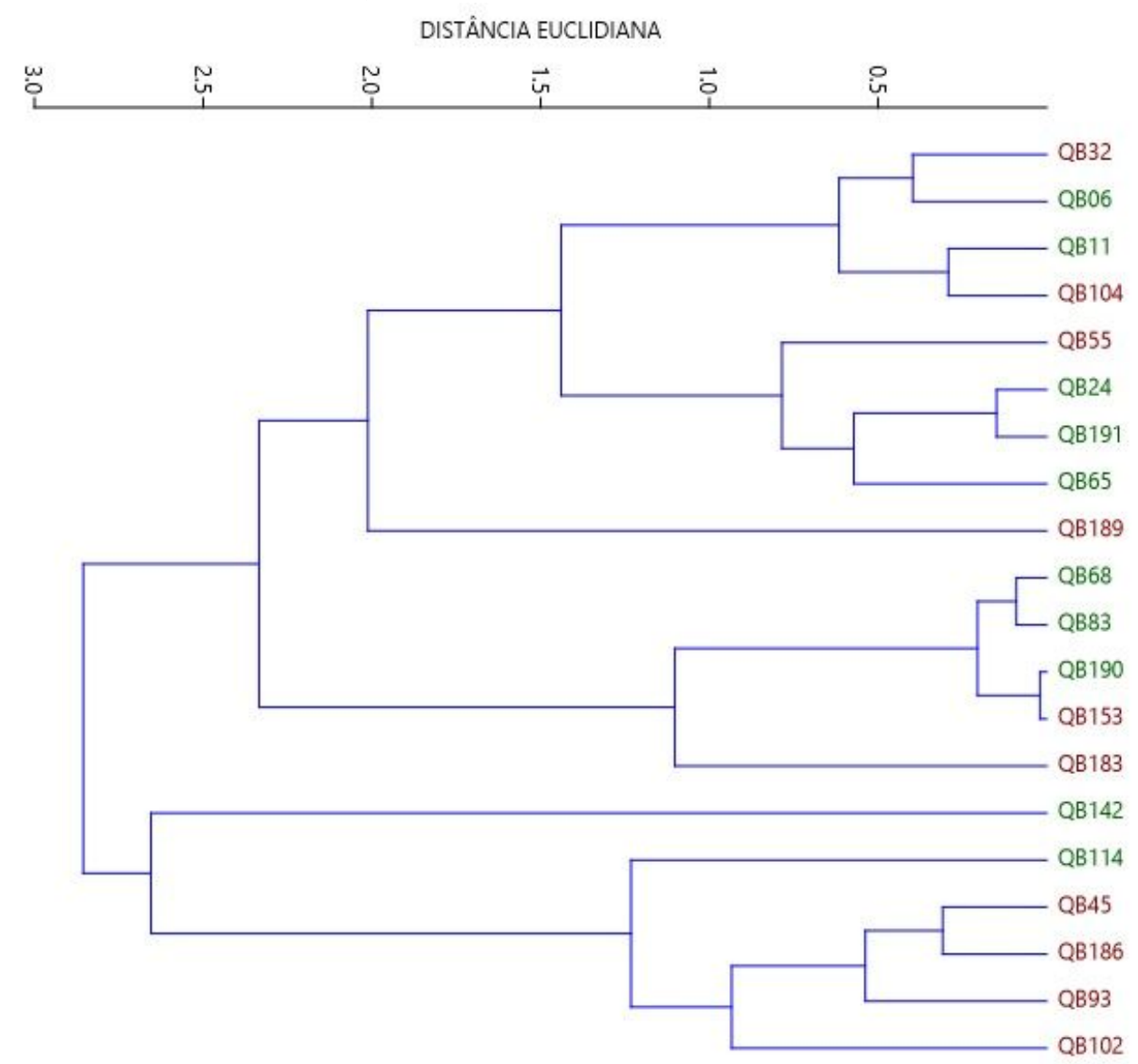

Fonte: Autores (2021)

Percebe-se que vários grupos foram formados e que as cepas são dissimilares em relação à sua atividade enzimática. Isso pode ser explicado primeiramente pela diversidade metabólica intrínseca das cepas bem como pelo efeito do fogo no solo que possivelmente causou seleção de cepas com potencial enzimático diferente daquele que havia antes do distúrbio. Além disso, as cepas pré e pós queimada não se agrupam entre si, o que reforça os resultados obtidos pela análise estatística, no qual evidenciou diferença estatística entre os IE das cepas considerando as três enzimas estudadas.

Em resumo, a temperatura é extremamente importante na regulação do crescimento e atividade fisiológica dos microrganismos, bem como na atividade das enzimas produzidas (KHVEDELIDZE et al., 2017). Imediatamente após a aplicação de fogo, os efeitos na comunidade microbiana são negativos, mas os microrganismos possuem capacidade de adaptar-se às mudanças ambientais (PRENDERGAST-MILLER et al., 2017 ; RODRÍGUEZ et al., 2018). Além disso, a atividade das enzimas hidrolíticas sofre modificação significativa após ação do fogo (SINGH et al., 2017). E por fim, é importante salientar que apesar do fogo ser um agente físico capaz de eliminar as diversas formas de vida na natureza, esse tem seu efeito mais pronunciado apenas na superfície do solo, o que permite a tolerância e sobrevivência da microbiota que habita a subsuperfície. 


\section{CONCLUSÃO}

A queimada afetou significativamente a produção das enzimas hidrolíticas extracelulares de cepas de actinobactérias isoladas do solo que pode ocasionar um desequilíbrio nas funções ecossistêmicas que essas desempenham.

A atividade amilolítica foi negativamente afetada pela queimada de modo que os índices enzimáticos das cepas isoladas após a queimada foram significativamente menores que os das cepas da área antes da aplicação de fogo.

As atividades celulolítica e xilanolítica foram aumentadas no solo submetido ao fogo, o que pode estar associado à capacidade de adaptação das actinobactérias às condições estressantes as quais são submetidas.

\section{AGRADECIMENTOS}

À Universidade Federal do Ceará e ao Laboratório de Microbiologia Ambiental por viabilizarem esse estudo.

\section{REFERÊNCIAS}

ALCAÑIZ, M.; OUTEIRO, L.; FRANCOS, M.; ÚBEDA, X. Effects of prescribed fires on soil properties: A review. Science of the Total Environment, v. 613, p. 944-957, 2018. DOI: https://doi.org/10.1016/j.scitotenv.2017.09.144

ALVES D. A. S.; SILVA V. M. A.; GARCIA F. A. C; MARTINS S. C. S.; MARTINS C. $M$. Produção de celulase e amilase por actinobactérias do semiárido brasileiro. Enciclopédia Biosfera, v.13, n.24; p.1303-1315, 2016. DOI: 10.18677/EnciBio_2016B_121

APARICIO, J. D.; BENIMELI C. S.; ALMEIDA, C. A.; POLTI, M. A.; COLIN V. L. Integral use of sugarcane vinasse for biomass production of actinobacteria: Potential application in soil remediation. Chemosphere; v.181, p 478-484, 2017. DOI: https://doi.org/10.1016/j.chemosphere.2017.04.107

ARAÚJO, S. M. S. A região semiárida do nordeste do Brasil: Questões ambientais e possibilidades de uso sustentável dos recursos. Rios-Eletrônica Revista Científica da FASETE, v. 5, p. 89-98, 2011. URL: https://www.unirios.edu.br/revistarios/media/revistas/2011/5/a_regiao_semiarida_do_ nordeste_do_brasil.pdf

BAYER, E. A.; LAMED, R. The cellulose paradox: pollutant par excellence and/or a reclaimable natural resource? Biodegradation, v. 3, n. 2-3, p.171-188, 1992. DOI: https://doi.org/10.1007/BF00129082

BEDADE, D.; BEREZINA, O.; SINGHAL, R.; DESKA, J.; SHAMEKH, S. Extracellular xylanase production from a new xylanase producer Tuber maculatum mycelium under submerged fermentation and its characterization. Biocatalysis and Agricultural Biotechnology, v. 11, p. 288-293, 2017. DOI: https://doi.org/10.1016/j.bcab.2017.07.008

BÖRJESSON, M.; LARSSON, A.; WESTMAN, G.; STRÖM, A. Periodate oxidation of xylan-based hemicelluloses and its effect on their thermal properties. Carbohydrate Polymers, v. 202, n. 15, p. 280-287, $2018 . \quad$ DOI: https://doi.org/10.1016/j.carbpol.2018.08.110 
BRECCIA, J.D.; CASTRO, G.R.; BAIGORI, M.D.; SIÑERIZ, F. Screening of xylanolytic bacteria using a colour plate method. Journal of Applied Bacteriology, v.78, p. 469-472, 1995. DOI: https://doi.org/10.1111/j.1365-2672.1995.tb03086.x

BUNEMANN, E. K.; BONGIORNOA, G.; BAIC, Z.; CREAMER, R. E.; DEYN, G.; et al., Soil quality - A critical review. Soil Biology and Biochemistry, v. 120, p.105125, 2018. DOI: https://doi.org/10.1016/j.soilbio.2018.01.030

CAVALCANTE, F. G.; MARTINS, C. M.; MARTINS, S. C. S. Interações bióticas entre actinobactérias e rizóbios em solos da região semiárida brasileira. Enciclopédia Biosfera, v.14 n.26; p. 1009-1029, 2017. DOI: 10.18677/EnciBio_2017B86

COLLINS, T.; GERDAY, C.; FELLER, G. Xylanases, xylanase families and extremophilic xylanases. FEMS Microbiology Reviews. v. 29, p. 3-23, 2005. DOI: https://doi.org/10.1016/j.femsre.2004.06.005

GEORGE S. P.; AHMAD, A.; RAO, M. B. A novel thermostable from Thermomonospora sp.: influence of additivies on thermostability. Bioresource Tecnhology. v. 78, p. 221-224, 2001. DOI: https://doi.org/10.1016/S09608524(01)00029-3

GOSAI, H. B.; SACHANIYA, B. K.; PANSERIYA, H. Z.; DAVE B. P. Functional and phylogenetic diversity assessment of microbial communities at Gulf of Kachchh, India: An ecological footprint. Ecological Indicators, v.93, p. 65-75, 2018. DOI: https://doi.org/10.1016/j.ecolind.2018.04.072

GREINER, L.; KELLER, A.; GRÊT-REGAMEY, A.; PAPRITZ, A. Soil function assessment: review of methods for quantifying the contributions of soils to ecosystem services. Land Use Policy, v. 69, p.224-237, 2017. DOI: https://doi.org/10.1016/j.landusepol.2017.06.025

GREINER, L.; NUSSBAUM, M.; PAPRITZ, A.; FRAEFEL, M.; ZIMMERMANN, S.; et al.; Assessment of soil multi-functionality to support the sustainable use of soil resources on the Swiss Plateau. Geoderma Regional, v.14, 2018. DOI: https://doi.org/10.1016/j.geodrs.2018.e00181

GUPTA, P.; SAMANT, K.; SAHU, A. Isolation of cellulose-degrading bacteria and determination of their cellulolytic potential. International Journal of Microbiology, v.6, p.1-5, 2012. DOI: https://doi.org/10.1155/2012/578925

HAMEDI J.; KAFSHNOUCHI, M.; RANJBARAN, M. A. Study on actinobacterial diversity of Hampoeil cave and screening of their biological activities. Saudi Journal of Biological Sciences. 2019. DOI: https://doi.org/10.1016/j.sjbs.2018.10.010

HAMEED, U.; PRICE, I.; IKRAM-UL-HAQ; KE, A.; WILSON, D. B.; MIRZA, O. Functional characterization and crystal structure of thermostable amylase from Thermotoga petrophila, reveals high thermostability and an unusual form of dimerization. BBA - Proteins and Proteomics, 2017. DOI: https://doi.org/10.1016/j.bbapap.2017.06.015 
HENDRICKS, C. W.; DOYLE, J. D.; HUGLEY, B. A new solid medium for enumerating cellulose-utilizing bacteria in soil. Applied and environmental

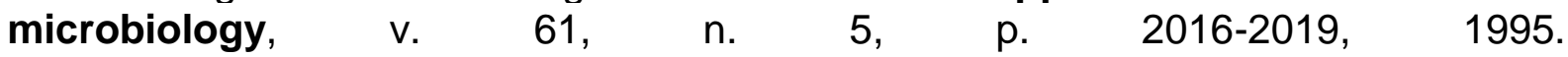
https://doi.org/10.1128/aem.61.5.2016-2019.1995

JANG, H. D.; CHEN, K. S. Production and characterization of thermostable cellulases from Streptomyces transformant T3-1. World Journal Microbiology and $\begin{array}{llll}\text { Biotechnology, } & \text { v.19, } & \text { n.3, 2003. } & \text { DOI: }\end{array}$ https://doi.org/10.1023/A:1023641806194

KHVEDELIDZE, R. M.; URUSHADZE, T. R.; KUTATELADZE, L.I.; TSIKLAURI, N. D, ZAKARIASHVILI, N. G.; ALEKSIDZE, T. I. Amilase-producing mikromycetes isolated from soils of South Caucasus. Annals of Agrarian Science, v. 15, p. 318-321, 2017. DOI: https://doi.org/10.1016/j.aasci.2017.07.005

KUMAR, V.; SHUKLA, P. Extracellular xylanase production from $T$. lanuginosus VAPS24 at pilot scale and thermostability enhancement by immobilization. Process $\begin{array}{llllll}\text { Biochemistry, } & \text { v. } & 71, & \text { p. } & 53-60, & 2018 .\end{array}$ https://doi.org/10.1016/j.procbio.2018.05.019

LACOMBE-HARVEY, M.; BRZEZINSKI, R.; BEAULIEU, C. Chitinolytic functions in actinobacteria: ecology, enzymes, and evolution. Applied microbiology and biotechnology, v. 102, n. 17, p. 7219-7230, 2018. https://doi.org/10.1007/s00253018-9149-4

LEHMANN, A.; ZHENG, W.; RILLIG, M. C. Soil biota contributions to soil aggregation. Nature Ecology \& Evolution, v. 1, n. 12, p. 1828-1835, 2017. https://doi.org/10.1038/s41559-017-0344-y

LIMA, A. L. G.; NASCIMENTO, R.P.; BOM, E. P. S.; COELHO, R. R. R. Streptomyces drozdowiczii celulase production using agro-industrial by-products and its potential use in the detergente and textile industries. Enzyme and Microbial Technology, v. $37, \quad$ n. 2 , p. 272-277, $2005 . \quad$ DOI: https://doi.org/10.1016/j.enzmictec.2005.03.016

LOPES, J. B. A. C.; SILVA, V. M. A.; CAVALCANTE, F. G.; MARTINS, S. C. S.; MARTINS, C. M. Produção de enzimas hidrolíticas extracelulares por Actinobactérias oriundas do solo e serrapilheira de região Semiárida. Enciclopédia Biosfera, v. 15 n. 27; p. 35 - 50, 2018. DOI: 10.18677/EnciBio_2018A93

MEIJ, A. V. D.; WORSLEY, S. F.; HUTCHINGS, M. I; G. P. VAN WEZEL, G. P. Chemical ecology of antibiotic production by actinomycetes. FEMS Microbiology Reviews, v. 41, n. 3, p. 392-416, 2017. DOI: https://doi.org/10.1093/femsre/fux005

MENDES, I. C.; DE SOUSA, D. M. G.; DOS REIS JUNIOR, F. B. Bioindicadores de qualidade de solo: dos laboratórios de pesquisa para o campo. Cadernos de

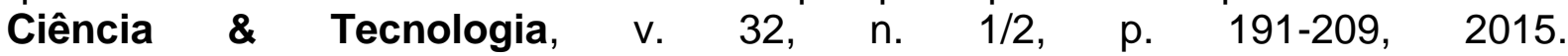
http://dx.doi.org/10.35977/0104-1096.cct2015.v32.23311 
MISHRA, S.; BEHERA, N. Amylase activity of a starch degrading bacteria isolated from soil receiving kitchen wastes. African journal of Biotechnology, v. 7, n. 18, p. 3326-3331, 2008. URL: https://www.ajol.info/index.php/ajb/article/view/59317/47615

MUNOZ-ROJAS M.; ERICKSONA, T. E.; MARTINIA, D. DIXONA, K. W.; MERRITTA, D. J. Soil physicochemical and microbiological indicators of short-, medium- and long-term post-fire recovery in semi-arid ecosystems. Ecological Indicators, v. 63, p. 14-22, 2016. DOI: https://doi.org/10.1016/j.ecolind.2015.11.038

NOUIOUI, I.; CARRO, L.; GARCÍA-LÓPEZ, M.; MEIER-KOLTHOFF, J. P.; WOYKE, T.; KYRPIDES, N. C.; GÖKER, M. Genome-based taxonomic classification of the phylum Actinobacteria. Frontiers in microbiology, v. 9, p. 2007, 2018. https://doi.org/10.3389/fmicb.2018.02007

OLIVEIRA, R. L.; BORBA, C. B. A.; JUNIOR, S. D.; ALBUQUERQUE, P. M.; LIMA G. M. S.; GUSMÃO, N. B.; ANDRADE, E. V.; SILVA, L. A. O. Production and characterization of endoglucanase secreted by Streptomyces capoamus isolated from Caatinga. African Journal of Biotechnology, v.15, p. 2394-2401, 2016. DOI: 10.5897/AJB2015.14610

PRENDERGAST-MILLER, M. T.; MENEZES A. B.; MACDONALD, L. M.; TOSCAS, P.; BISSETT, A.; GEOFF BAKER, G.; FARRELL, M.; RICHARDSON, A. E.; WARK, T.; THRALL, P. H. Wildfire impact: Natural experiment reveals differential short-term changes in soil microbial communities. Soil Biology \& Biochemistry. v. 109, p. 113, 2017. DOI: https://doi.org/10.1016/j.soilbio.2017.01.027

RODRÍGUEZ, J.; GONZÁlEZ-PÉREZ, J. A.; TURMERO, A.; HERNÁNDEZ, M.; BALL, A. S.; et al.; Wildfire effects on the microbial activity and diversity in a Mediterranean forest soil. Catena, v.158, p. 82-88, 2017. DOI: https://doi.org/10.1016/j.catena.2017.06.018

RODRÍGUEZ, J.; GONZÁLEZ-PÉREZ, J. A.; TURMERO, A.; HERNÁNDEZ, M.; BALL, A. S.; GONZÁLEZ-VILA, F. J.; ARIAS, M. E. Physico-chemical and microbial perturbations of Andalusian pine forest soils following a wildfire. Science of the Total $\begin{array}{llllll}\text { Environment. } & v . & 634, & \text { p. } & 650-660, & 2018 .\end{array}$ https://doi.org/10.1016/j.scitotenv.2018.04.028

SANJIVKUMAR, M.; SILAMBARASAN, T.; PALAVESAM, A.; IMMANUEL, G. Biosynthesis, purification and characterization of $\beta-1,4-x y l a n a s e$ from a novel mangrove associated actinobacterium Streptomyces olivaceus (MSU3) and its applications. Protein expression and purification, v. 130, p. 1-12, 2017. https://doi.org/10.1016/j.pep.2016.09.017

SINGH, A. K.; KUSHWAHA, M.; RAI, A.; SINGH, N. Changes in soil microbial response across year following a wildfire in tropical dry forest. Forest Ecology and $\begin{array}{lllll}\text { Management, } & \text { v.391, } & \text { p. } & 458-468, & \text { DOI: }\end{array}$ https://doi.org/10.1016/j.foreco.2017.02.042

SOUZA, A. F. S.; PEREIRA, S. M. F. As queimadas no Parque Nacional de Sete Cidades: uma ameaça para a conservação da biodiversidade. Revista SOMMA, v. 
5 ,

n. $\quad 1, \quad$ p.

102-109,

2019.

URL:

http://ojs.ifpi.edu.br/revistas/index.php/somma/article/download/728/238.

STAMFORD, T.L.M., STAMFORD, N.P., ARAUJO, J.M. Atividade enzimática de microrganismos isolados do jacatupé (Pachyrhizus erosus L. Urban). Ciência e Tecnologia de Alimentos, v. 18, n. 4, p. 382-385, 1998. DOI: https://doi.org/10.1590/S0101-20611998000400004

VAIKUNDAMOORTHY, R.; RAJENDRAN, R.; SELVARAJU, A.; MOORTHY K.; PERUMAL S. Development of thermostable amylase enzyme from Bacillus cereus for potential antibiofilm activity. Bioorganic Chemistry, v. 77, p. 494-506, 2018. DOI: https://doi.org/10.1016/j.bioorg.2018.02.014 